\title{
Performance of Prediction Models for Contrast-Induced Acute Kidney Injury after Transcutaneous Aortic Valve Replacement
}

\author{
Vitor E.E. Rosa ${ }^{\mathrm{a}, \mathrm{b}}$ Carlos M. Campos ${ }^{\mathrm{b}, \mathrm{c}}$ Antonio Bacelar ${ }^{\mathrm{a}}$ \\ Alexandre A.C. Abizaid ${ }^{b}$ José A. Mangioned Pedro A. Lemos ${ }^{a}$ b \\ Vinicius Esteves ${ }^{e}$ Paulo Caramori ${ }^{f}$ Roney O. Sampaio ${ }^{b}$ Flávio Tarasoutchi ${ }^{a} b$ \\ Roxana Mehran ${ }^{g}$ Fabio S. Brito Jr ${ }^{b, h}$ \\ ${ }^{a}$ Hospital Israelita Albert Einstein, São Paulo, Brazil; b Heart Institute (InCor), University of São Paulo Medical School,

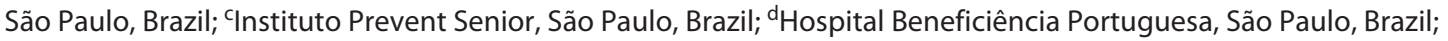

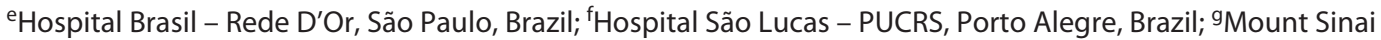 \\ Medical Center, New York, NY, USA; h'Hospital Sírio-Libanês, São Paulo, Brazil
}

\begin{abstract}
Background: Acute kidney injury (AKI) has shown to adversely affect outcomes in patients undergoing transcutaneous aortic valve replacement (TAVR), and its correct risk estimation may interfere in procedural planning and strategies. The aim of the study was to test and compare 6 scores in predicting AKI after TAVR. Methods: We tested 6 scores (the contrast material limit score, volume-to-creatinine clearance ratio, ACEF, CR4EATME3AD3, Mehran model A, and Mehran model $B$ ) in a total of 559 consecutive patients included in the Brazilian TAVR registry. Results: All scores had a poor accuracy and calibration to predict the occurrence of AKI grade 1 or 2 . All scores improved the accuracy of AKI risk prediction when stratified for AKI grade 2/3 and AKI grade 3 for all scores. The CR4EATME3AD3 was the best predictor of AKI stage 2/3 (AUC: 0.62; OR: 1.12;95\% Cl 1.01-1.26; $p=0.04$ ) and AKI stage 3 (AUC: 0.64; OR: 1.16; 95\% Cl 1.02-1.32; $p=0.02$ ). Mehran models $A$ and $B$ were both good models for AKI stage 3 (AUC: $0.63 ;$ OR: $1.10 ; 95 \% \mathrm{Cl} 1.01-1.22 ; p=0.05$; and AUC: 0.62 ; OR: $1.10 ; 95 \% \mathrm{Cl} 1.00-1.21 ; p=0.05$, respectively). Conclusions: None of the current models demonstrated validity in detecting AKI when its lower grades were evaluated.
\end{abstract}

CR4EATME3AD3 was the best score in predicting moderate to severe AKI after TAVR. These findings suggest that contrast-induced AKI may not be the only factor related to kidney injury after TAVR.

(c) 2021 The Author(s)

Published by S. Karger AG, Basel

\section{Introduction}

The advent of transcutaneous aortic valve replacement (TAVR) has been established as an alternative, less-invasive treatment for aortic stenosis. International guidelines recommend TAVR as a class I indication for symptomatic patients with severe aortic stenosis who have high-surgical risk or are not candidates for surgery $[1,2]$. Recently, TAVR has been considered also for moderateand low-risk patients [3-7].

Patients undergoing TAVR are commonly elderly with a high prevalence of comorbidities. Among these conditions, renal dysfunction is a relevant medical issue for elderly patients with severe aortic stenosis. Both baseline and post-procedural renal failure are risk factors for

Correspondence to:

Carlos M. Campos, carlosacampos1@gmail.com

karger@karger.com www.karger.com/crm

Karger $\stackrel{\text { ' }}{5}$

BOPEN ACCESS
(C) 2021 The Author(s)

Published by S. Karger AG, Basel

This is an Open Access article licensed under the Creative Commons Attribution-NonCommercial-4.0 International License (CC BY-NC) (http://www.karger.com/Services/OpenAccessLicense), applicable to the online version of the article only. Usage and distribution for commercial purposes requires written permission. 
Table 1. Risk scores for AKI after cardiac angiography and/or PCI

\begin{tabular}{|c|c|c|}
\hline Risk score & Formula/variables & Prediction \\
\hline Contrast material limit score & $(5 \times$ body weight $[\mathrm{kg}])$ divided by serum creatinine $(\mathrm{mg} / \mathrm{dL})$ & $\begin{array}{l}\text { Risk of AKI in patients with renal disease undergoing cardiac } \\
\text { catheterization and angiography }\end{array}$ \\
\hline $\begin{array}{l}\text { Volume-to-creatinine } \\
\text { clearance ratio }\end{array}$ & Contrast volume divided by creatinine clearance & $\begin{array}{l}\text { Value }>3.7 \text { predicts an increase of creatinine in early-PCI patients } \\
(24-48 \mathrm{~h})\end{array}$ \\
\hline ACEF score & Age/ejection fraction $(\%)+1$ (if serum creatinine $\geq 2.0 \mathrm{mg} / \mathrm{dL}$ ) & $\begin{array}{l}\text { Risk of AKI within } 72 \mathrm{~h} \text { after coronary angiography with or } \\
\text { without PCI: low risk (score }<1.2) \text {, medium risk }(1.2-1.5 \text { score), } \\
\text { and high risk (score }>1.5)\end{array}$ \\
\hline CR4EATME3AD3 & $\begin{array}{l}\text { Contrast volume }>200 \mathrm{~mL} \text { ( } 2 \text { score), eGFR }<60 \mathrm{~mL} / \mathrm{min} / 1.73 \mathrm{~m}^{2} \text { ( } 4 \text { score), emergency PCI ( } 2 \text { score), age }>70 \\
\text { years ( } 2 \text { score), hypotension ( } 2 \text { score), history of myocardial infarction ( } 2 \text { score), left ventricular ejection } \\
\text { fraction }<45 \% \text { ( } 3 \text { score), anemia ( } 2 \text { score), and diabetes mellitus ( } 3 \text { score) }\end{array}$ & $\begin{array}{l}\text { Risk of post-PCI AKI after } 48-72 \mathrm{~h} \text { of the procedure in patients } \\
\text { older than } 65 \text { years: low risk (score } \leq 4) \text {, medium risk ( } 5-8 \text { score), } \\
\text { high risk ( } 9-12 \text { score), and very high risk (score } \geq 13 \text { ) }\end{array}$ \\
\hline Mehran model A & $\begin{array}{l}\text { Hypotension ( } 5 \text { score), intra-aortic balloon pump use ( } 5 \text { score), congestive heart failure ( } 5 \text { score), serum } \\
\text { creatinine }>1.5 \mathrm{mg} / \mathrm{dL} \text { ( } 4 \text { score), age greater than } 75 \text { years ( } 4 \text { score), anemia ( } 3 \text { score), diabetes mellitus } \\
\text { ( } 3 \text { score), and contrast volume ( } 1 \text { for } 100 \mathrm{~mL} \text { ) }\end{array}$ & $\begin{array}{l}\text { Risk of AKI after } 48 \mathrm{~h} \text { of PCI: low risk (score } \leq 5) \text {, medium risk } \\
(6-10 \text { score), high risk (11-15 score), and very high risk (score } \\
\geq 16)\end{array}$ \\
\hline Mehan model B & $\begin{array}{l}\text { Congestive heart failure ( } 5 \text { score), hypotension ( } 5 \text { score), intra-aortic balloon pump use ( } 5 \text { score), age greater } \\
\text { than } 75 \text { years ( } 4 \text { score), anemia ( } 3 \text { score), diabetes mellitus }(3 \text { score), contrast volume ( } 1 \text { for } 100 \mathrm{~mL}) \text {, and eGFR } \\
\text { (1 for } 100 \mathrm{~mL}, 2 \text { for } 40-60 \mathrm{~mL}, 4 \text { for } 20-40 \mathrm{~mL} \text {, and } 6 \text { for }<20 \mathrm{~mL} \text { ) }\end{array}$ & $\begin{array}{l}\text { Risk of AKI after } 48 \mathrm{~h} \text { of PCI: low risk (score } \leq 5) \text {, medium risk } \\
(6-10 \text { score), high risk ( } 11-15 \text { score), and very high risk (score } \\
\geq 16)\end{array}$ \\
\hline
\end{tabular}

AKI, acute kidney injury; PCI, percutaneous coronary intervention; eGFR, estimated glomerular filtration rate.

increased mortality and complications after TAVR $[8,9]$. Specifically, TAVR-related acute kidney injury (AKI) is frequently observed and is related to higher all-cause mortality, cardiovascular mortality, myocardial infarction, and life-threatening bleeding $[10,11]$. However, current available risk scores for AKI have not been validated for patients undergoing TAVR. Thus, the aim of the present study was to test and compare the predictive performance of 6 scores for different grades of contrast-induced AKI after TAVR.

\section{Methods}

\section{Study Population}

From January 2008 to January 2015, 819 consecutive patients with symptomatic severe aortic stenosis underwent TAVR and were included in the multicentric TAVR Brazilian registry [12]. Patients with paradoxical aortic stenosis underwent calcium score computed tomography to confirm aortic stenosis severity. Twentytwo sites from different regions of Brazil participated in the study. For each patient, baseline characteristics, procedure details, and follow-up data were collected and recorded in a Web-based case report form designed especially for this registry. To better understand the risk of AKI following TAVR, we excluded 25 patients who died in the first $24 \mathrm{~h}$ after the procedure. Two hundred thirty-five participants did not have all the information that were necessary to calculate all 6 scores and were excluded from the present study. U1timately, 559 subjects were included in this analysis. The estimated glomerular filtration rate was calculated using the Levey formula [13]. The study protocol was conducted in accordance with the Declaration of Helsinki and was approved by each institution's Ethics Committee under protocol number 05676012.4.1001.00701.

\section{Procedure}

TAVR procedures were performed according to standard techniques. The transfemoral vascular approach was the first choice of access. The self-expandable CoreValve (Medtronic, Minneapolis, MN, USA), the balloon-expandable SAPIEN XT (Edwards Life- sciences, Irvine, CA, USA), and the balloon-expandable Inovare (Braile Biomedica, Sao Jose do Rio Preto, SP, Brazil) prostheses were used.

\section{AKI Definitions}

All outcomes were described according to the Valve Academic Research Consortium-2 (VARC-2) [10] criteria as follows

- Increase in serum creatinine to $150-199 \%(1.5-1.99 \times$ increase compared with baseline) or increase of $\geq 0.3 \mathrm{mg} / \mathrm{dL}(\geq 26.4$ $\mathrm{mmol} / \mathrm{L}$ ).

- Increase in serum creatinine to $200-299 \%(2.0-2.99 \times$ increase compared with baseline).

- Increase in serum creatinine to $\geq 300 \%$ ( $>3 \times$ increase compared with baseline) or serum creatinine of $\geq 4.0 \mathrm{mg} / \mathrm{dL}(\geq 354 \mathrm{mmol} / \mathrm{L})$ with an acute increase of at least $0.5 \mathrm{mg} / \mathrm{dL}(44 \mathrm{mmol} / \mathrm{L})$.

Acute kidney recovery was defined as a $25 \%$ improvement in the glomerular filtration rate at $48 \mathrm{~h}$ after the procedure [14].

\section{Risk Scores}

We searched in PubMed (www.ncbi.nlm.nih.gov/pubmed/) using a combination of specific key words that included "acute kidney injury," "contrast-induced nephropathy," "contrast-induced acute kidney injury," "creatinine increase," "risk prediction," "coronary catheterization," and "percutaneous coronary intervention." We found 6 scores, and they were tested and compared for the aforementioned grades of contrast-induced AKI after TAVR (Table 1): the contrast material limit score was calculated using the formula $(5 \times$ body weight $[\mathrm{kg}])$ divided by serum creatinine $(\mathrm{mg} / \mathrm{dL})$ [15]. The volume-to-creatinine clearance ratio evaluates the systemic exposure of the contrast [16]. The ACEF score (age, serum creatinine, and left ventricular ejection fraction) uses the formula age/ejection fraction (\%) +1 (if serum creatinine $\geq 2.0$ $\mathrm{mg} / \mathrm{dL}$ ) [17]. CR4EATME3AD3 uses a contrast volume $>200 \mathrm{~mL}$ ( 2 points), estimated glomerular filtration rate $<60 \mathrm{~mL} / \mathrm{min} / 1.73$ $\mathrm{m}^{2}$ (4 points), emergency procedure ( 2 points), age $>70$ years $(2$ points), hypotension ( 2 points), previous myocardial infarction (2 points), left ventricular ejection fraction $<45 \%$ ( 3 points), anemia ( 2 points), and diabetes mellitus ( 3 points) [18]. The Mehran model A variables are hypotension (5 points), intra-aortic balloon pump use ( 5 points), congestive heart failure ( 5 points), serum creatinine $>1.5 \mathrm{mg} / \mathrm{dL}$ ( 4 points), age over 75 years ( 4 points), anemia (3 points), diabetes mellitus ( 3 points), and contrast volume 
(1 point for $100 \mathrm{~mL}$ ) [19]. The Mehan model B is composed of congestive heart failure (5 points), hypotension (5 points), intraaortic balloon pump use ( 5 points), age greater than 75 years ( 4 points), anemia ( 3 points), diabetes mellitus ( 3 points), contrast volume ( 1 point for $100 \mathrm{~mL}$ ), and estimated glomerular filtration rate ( 1 point for $100 \mathrm{~mL}, 2$ for $40-60 \mathrm{~mL}, 4$ for $20-40 \mathrm{~mL}$, and 6 for $<20 \mathrm{~mL}$ ) [19].

\section{Data Analysis}

Continuous variables were presented as mean \pm standard deviation, and categorical variables were presented as frequencies. The first validation step consisted of assessing discrimination by the comparison of the area under the receiver operating characteristic curves. The second step was assessing calibration in the large, which compares the mean predicted probability and the mean observed frequency of AKI in the validation data. The ideal value is zero difference. Afterward, we performed graphical assessment in a calibration plot and estimation of a calibration slope. The last validation was estimating the predictor effects of each model in a univariate logistic regression model (using enter method). The scores of 30-day and overall mortality prediction were assessed using univariate and multivariate logistic regression and Cox regression, respectively. Variables with a $p$ value $\leq 0.05$ in the univariate model were included in the multivariate model. All probability values reported are 2 -sided, and a probability value $\leq 0.05$ was considered significant.

\section{Results}

\section{Patient Characteristics}

The baseline characteristics are shown in Table 2. The present study included 559 patients, with a mean age of $81.4 \pm 7.3$ years, $49.9 \%$ male and $81.6 \%$ with NYHA functional class III or IV. Chronic kidney disease, defined as an estimated glomerular filtration rate $<60 \mathrm{~mL} / \mathrm{min} / 1.73$ $\mathrm{m}^{2}$, was found in $76.6 \%$ of patients, the mean creatinine was $1.28 \pm 0.75 \mathrm{~mL} / \mathrm{dL}$, and the mean estimated glomerular filtration rate was $48.73 \pm 22.43 \mathrm{~mL} / \mathrm{min} / 1.73 \mathrm{~m}^{2}$. The mean logistic EuroSCORE was $20.06 \pm 14.24 \%$ and STS PROM $20.06 \pm 14.24 \%$.

Table 2 depicts baseline echocardiography and computerized tomography data. The mean aortic valve area was $0.67 \pm 0.18 \mathrm{~cm}^{2}$, mean transaortic gradient was 48.5 $\pm 15.6 \mathrm{~mm} \cdot \mathrm{Hg}$, and left ventricular ejection fraction was $58.4 \pm 15.0 \%$. The mean aortic valve diameter annulus was $23.02 \pm 3.09 \mathrm{~mm}$.

\section{TAVR Procedure}

Five hundred twenty-two patients (93.4\%) underwent transfemoral access TAVR. The prostheses used were CoreValve (70.5\%), SAPIEN XT (27.0\%), and Inovare (2.5\%). The mean contrast media volume during the procedure was $184.92 \pm 103.65 \mathrm{~mL}$, and $5 \%$ underwent percutaneous coronary intervention with the same procedure.
Table 2. Baseline characteristics

\begin{tabular}{|c|c|}
\hline Characteristic & $n=559$ \\
\hline \multicolumn{2}{|l|}{ Clinical data } \\
\hline Age, years & $81.4 \pm 7.3$ \\
\hline Body mass index, $\mathrm{kg} / \mathrm{m}^{2}$ & $26.3 \pm 4.7$ \\
\hline Male, $n(\%)$ & $279(49.9)$ \\
\hline NYHA I/II, $n(\%)$ & $103(18.4)$ \\
\hline NYHA III/IV, $n(\%)$ & $456(81.6)$ \\
\hline Diabetes mellitus, $n(\%)$ & $189(33.8)$ \\
\hline Hypertension, $n(\%)$ & $426(76.2)$ \\
\hline Dyslipidemia, $n(\%)$ & $278(49.7)$ \\
\hline COPD, $n(\%)$ & $107(19.1)$ \\
\hline Coronary artery disease, $n(\%)$ & $332(59.4)$ \\
\hline Peripheral arterial disease, $n(\%)$ & $98(17.5)$ \\
\hline Porcelain aorta, $n(\%)$ & $45(8.1)$ \\
\hline Previous stroke or TIA, $n(\%)$ & $46(8.2)$ \\
\hline CKD $\left(\mathrm{eGFR}<60 \mathrm{~mL} / \mathrm{min} / 1.73 \mathrm{~m}^{2}\right), n(\%)$ & $428(76.6)$ \\
\hline Logistic EuroSCORE, \% & $20.06 \pm 14.24$ \\
\hline STS PROM, \% & $10.41 \pm 7.8$ \\
\hline \multicolumn{2}{|l|}{ Medications } \\
\hline ACE inhibitors or ARB, $n(\%)$ & $289(51.7)$ \\
\hline Diuretics, $n(\%)$ & $362(64.8)$ \\
\hline Statins, $n(\%)$ & $334(59.7)$ \\
\hline \multicolumn{2}{|l|}{ Laboratory data } \\
\hline Hemoglobin, g/dL & $11.8 \pm 1.7$ \\
\hline Platelet count, $\mathrm{mm}^{3}$ & $201,290 \pm 72,668$ \\
\hline Creatinine, mg/dL & $1.28 \pm 0.75$ \\
\hline $\mathrm{eGFR}, \mathrm{mL} / \mathrm{min} / 1.73 \mathrm{~m}^{2}$ & $48.73 \pm 22.43$ \\
\hline \multicolumn{2}{|l|}{ Echocardiographic data } \\
\hline Aortic valve area, $\mathrm{cm}^{2}$ & $0.67 \pm 0.18$ \\
\hline Left ventricular ejection fraction, $\%$ & $58.4 \pm 15.0$ \\
\hline Left ventricular end-diastolic diameter, $\mathrm{mm}$ & $51.2 \pm 9.2$ \\
\hline Peak transaortic gradient, $\mathrm{mm} \cdot \mathrm{Hg}$ & $79.6 \pm 23.5$ \\
\hline Mean transaortic gradient, $\mathrm{mm} \mathrm{Hg}$ & $48.5 \pm 15.6$ \\
\hline \multicolumn{2}{|l|}{ CT data } \\
\hline Aortic valve mean diameter annulus, $\mathrm{mm}$ & $23.02 \pm 3.09$ \\
\hline
\end{tabular}

Values are $n(\%)$ or mean $( \pm \mathrm{SD})$. ACE, angiotensin-convertingenzyme; ARB, angiotensin II receptor blocker; CKD, chronic kidney disease; COPD, chronic obstructive pulmonary disease; CT, computerized tomography; eGFR, estimated glomerular filtration rate; NYHA, New York Heart Association; PCI, percutaneous coronary intervention; TIA, transient ischemic attack.

\section{Outcomes}

According to VARC-2 definition, $17.9 \%$ patients ( $n=$ $100)$ had post-procedure AKI, $11.8 \%(n=66)$ had AKI stage $1,1.3 \%(n=7)$ had AKI stage 2 , and $4.8 \%(n=27)$ had AKI stage 3.

\section{Predictive Performance of Risk Scores}

Figure 1 summarizes the metrics used in the present study to assess the performance of the risk models. All 6 scores had poor accuracy and calibration to predict the 


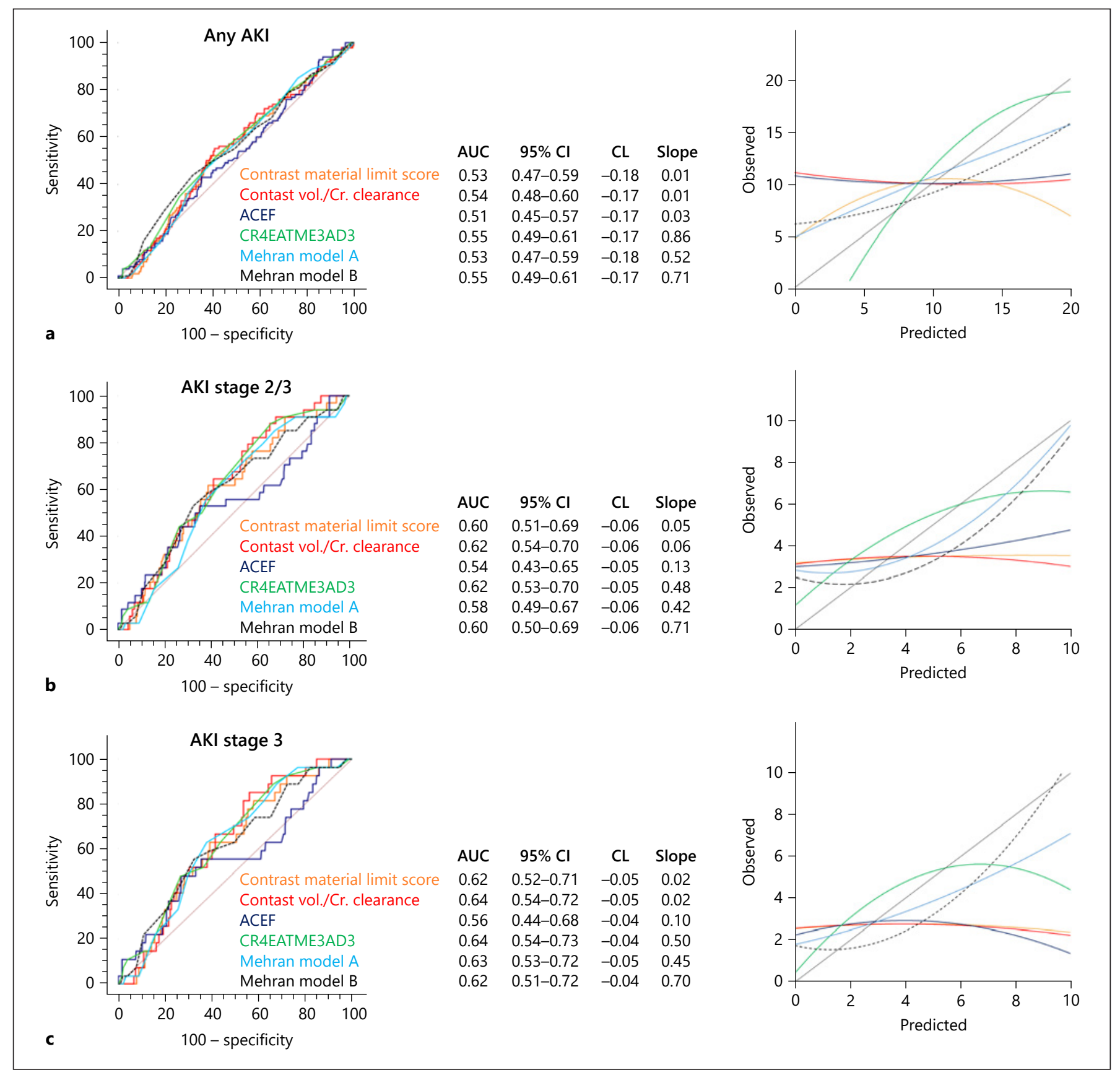

Fig. 1. Predictive performance of risk scores for prediction of AKI after TAVR. Left panels show the ROC curves of the 6 scores for prediction of any AKI (a); AKI stage 2/3 (b), and AKI stage 3 (c). Right panels are calibration plots for $\%$ of predicted and observed risk among quintiles for the 6 tested scores. AUC, area under ROC curve; $\mathrm{CI}$, confidence interval; CL, calibration in the large; Vol, volume $(\mathrm{mL})$; Cr, creatinine $(\mathrm{mg} / \mathrm{dL})$; AKI, acute kidney injury; TAVR, transcutaneous aortic valve replacement; ROC, receiver operating characteristic.

occurrence of any AKI (contrast material limit score 0.53, volume-to-creatinine clearance ratio 0.54, ACEF 0.51, CR4EATME3AD3 0.55, Mehran model A 0.53, and Mehran model B 0.55) (Fig. 1a). None of the models demon- strated to have significant validity in predicting AKI stages 1,2 , and 3 (Table 3 ).

There was an improvement in AKI risk prediction when stratified for AKI grades $2 / 3$ (Fig. 1b) for all 
scores. The calibration in the large decreased for all scores, and the AUC also demonstrated higher accuracy. In the logistic regression analysis, only CR4EATME3AD3 was a predictor of AKI stages 2 or 3 (odds ratio: 1.12 ; $95 \%$ confidence interval $1.01-1.26 ; p=0.04$; Table 3).

For severe AKI (grade 3), the scores showed further improvement in their predictive performance when tested for AKI stage 3 for discrimination and calibration (Fig. 1c). CR4EATME3AD3, Mehran model A, and Mehran model B were able to predict AKI stage 3. CR4EATME3AD3 demonstrated to have the best numerical discrimination, and Mehran model B have the best calibration (higher slope and lower calibration in the large, Fig. 1c). Overall, the CR4EATME3AD3 score had the best performance as assessed by the combination of discrimination, calibration, and higher odds ration coefficients.

\section{General Anesthesia and Conscious Sedation}

Forty-five patients (8.1\%) underwent conscious sedation and 514 (91.9\%) general anesthesia. General anesthesia was not a predictor of any AKI (odds ratio: 1.814; $95 \%$ confidence interval 0.697-4.718; $p=0.222$ ) or severe AKI (grade 3) (odds ratio: 2.344; 95\% confidence interval $0.311-17.689 ; p=0.409)$.

\section{Risk Scores Mortality Prediction}

The contrast material limit score and volume-to-creatinine clearance ratio were the only 30 -day mortality predictors in the univariate analysis (see online suppl. Table 1; for all online suppl. material, see www.karger. com/doi/10.1159/000517058). However, only the volume-to-creatinine clearance ratio remained an independent predictor in the multivariate analysis (odds ratio: $1.432 ; 95 \%$ confidence interval $1.037-1.977 ; p=$ 0.029; online suppl. Table 1). Regarding the overall mortality, none of the present scores was a predictor of long-term mortality. The median follow-up was 372 (89-730) days.

\section{Acute Kidney Recovery}

Forty-five patients (8.5\%) had improvement in the glomerular filtration rate after TAVR. AKI was a predictor of overall mortality when compared to acute kidney recovery and unchanged glomerular filtration rate (odds ratio: 2.913; 95\% confidence interval 1.972-4.302; $p<$ 0.001 for AKI; odds ratio: 1.205 ; $95 \%$ confidence interval $0.598-2.425 ; p=0.602$ for acute kidney recovery; and unchanged glomerular filtration rate as reference).
Table 3. Logistic regression coefficients of risk models for different degrees of AKI after TAVR

\section{OR} $p$ value

\section{Any AKI}

Contrast material limit score

Volume-to-creatinine clearance ratio ACEF

CR4EATME3AD3

Mehran model A

Mehran model B

AKI stage $2 / 3$

Contrast material limit score

Volume-to-creatinine clearance ratio ACEF

CR4EATME3AD3

Mehran model A

Mehran model B

AKI stage 3

Contrast material limit score

Volume-to-creatinine clearance ratio ACEF

CR4EATME3AD3

Mehran model A

Mehran model B

$\begin{array}{ll}0.96(0.88-1.04) & 0.40 \\ 0.98(0.93-1.04) & 0.68 \\ 1.03(0.74-1.43) & 0.84 \\ 1.06(0.99-1.13) & 0.10 \\ 1.02(0.97-1.08) & 0.41 \\ 1.04(0.98-1.08) & 0.16 \\ & \\ 1.02(0.92-1.12) & 0.68 \\ 1.02(0.96-1.10) & 0.44 \\ 1.40(0.94-2.06) & 0.10 \\ 1.12(1.01-1.26) & 0.04 \\ 1.06(0.97-1.16) & 0.21 \\ 1.07(0.99-1.17) & 0.09 \\ & \\ 1.02(0.91-1.14) & 0.77 \\ 1.02(0.94-1.10) & 0.61 \\ 1.45(0.95-2.19) & 0.08 \\ 1.16(1.02-1.32) & 0.02 \\ 1.10(1.01-1.22) & 0.05 \\ 1.10(1.00-1.21) & 0.05\end{array}$

AKI, acute kidney injury; TAVR, transcutaneous aortic valve replacement.

\section{Discussion}

The main findings of our study were (1) all 6 scores had poor accuracy to predict the occurrence of AKI at earlier stages; (2) there was an improvement in their predictive performance for assessing advanced AKI; and (3) CR4EATME3AD3 had the best accuracy in prediction of AKI grade $2 / 3$ and AKI grade 3 .

The present work is the first study to assess and compare the predictive performance of previously validated scores (contrast material limit score; volume-to-creatinine clearance ratio; ACEF; CR4EATME3AD3; Mehran model A, and Mehran model B) for different grades of contrast-induced AKI in patients undergoing TAVR. This topic is of major clinical relevance since AKI after TAVR has marked prognostic implications [10].

It has been shown that significant AKI (stage 2 or 3 ) was associated with an increase in all-cause mortality, mainly in more advanced stages, including those who required dialysis [11, 20-22]. Thus, although the models had poor accuracy in detecting lower risk of AKI, stage $2 / 3$ is the most clinically relevant. Furthermore, post-procedure AKI is also related to higher incidence of cardio- 
Table 4. Risk categories of AKI according to the CR4EATME3AD3 score

\begin{tabular}{lllll}
\hline & $\begin{array}{l}\text { Low-risk } \\
(0-7 \text { points }) \\
N=181\end{array}$ & $\begin{array}{l}\text { Intermediate-risk } \\
(8-9 \text { points })\end{array}$ & $\begin{array}{l}\text { High-risk } \\
(>10 \text { points }) \\
N=208\end{array}$ & $p$ value \\
\hline Any AKI stage, \% & 14.9 & 16.5 & 21.6 & 0.19 \\
AKI stages 2/3. \% & 2.2 & 7.6 & 8.2 & 0.03 \\
AKI stage 3, \% & 1.7 & 5.9 & 6.7 & 0.05 \\
\hline
\end{tabular}

AKI, acute kidney injury. vascular mortality, cerebrovascular accidents, and myocardial infarction $[11,22]$. Unexpectedly, only the volume-to-creatinine clearance ratio was an independent predictor of 30-day mortality. However, the volume-tocreatinine clearance ratio was not validated for mortality purpose, so this finding should be analyzed carefully. Besides, a previous study demonstrated that the impact of AKI on long-term mortality is limited, supporting the fact that no score predicted long-term mortality in our study [11].

Previous chronic kidney disease has uncertain impact on post-procedure $A K I[23,24]$. In a previous study from the Brazilian registry, chronic kidney disease was not an independent predictor of AKI after TAVR [11]. However, all scores evaluated in our work included serum creatinine or the estimated glomerular filtration rate.

Choosing a risk score model is important to balance its statistical precision, clinical applicability, and computational readiness [25]. Numerically, CR4EATME3AD3 had the best accuracy in prediction of AKI grade $2 / 3$ and AKI grade 3. Mehran models A and B also had fair accuracy in detecting $\mathrm{AKI}$, but only in its severe state. CR4EATME3AD3 and Mehran models use similar variables as source for estimating the risk of AKI. However, CR4EATME3AD3 should also be considered because it is simpler to calculate.

CR4EATME3AD3 was developed to evaluate the risk of contrast-induced AKI 48-72 h post-percutaneous coronary intervention. This score system stratifies patients into low risk (score $\leq 4)$, medium risk (5-8 score), high risk (9-12 score), and very high risk (score $\geq 13$ ) [18]. The present work is the first to validate CR4EATME3AD3 in a TAVR population. In the present population however, we propose to classify the patients in different categories: low risk of TAVR-related AKI ( $<7$ points), intermediate risk (8-9 points), and high risk (>10 points). These categories were based on CR4EATME3AD3 tertiles and were able to discriminate different categories of AKI (Table 4).

Scores for Kidney Injury after TAVR
None of the scores however had perfect calibration, that is, perfect correlation between the percentage of predicted and the percentage of observed risks among quintiles. Thus, the role of new renal biomarkers of AKI, such as $\mathrm{N}$-acetyl- $\beta$-D-glucosaminidase, kidney injury molecule-1, neutrophil gelatinase-associated lipocalin, insulin-like growth factor-binding protein 7 , and the tissue inhibitor of metalloproteinases-2, needs to be explored. $\mathrm{N}$-acetyl- $\beta$-D-glucosaminidase, kidney injury molecule-1, and neutrophil gelatinase-associated lipocalin are good biomarkers of contrast-induced AKI, though in situations other than TAVR [26-29]. Until now, only 2 prospective studies addressed this issue in the TAVR population $[30,31]$. Both evaluated insulin-like growth factorbinding protein 7 and tissue inhibitor of metalloproteinases- 2 as tools for post-TAVR early AKI detection, but results were conflicting, and new studies are required to clarify the real predictive impact of these biomarkers.

Unlike other diagnostic or therapeutic procedures using iodine media and apart from the nephrotoxicity itself of the contrast, TAVR may provide an immediate hemodynamic improvement, with reduction in left ventricle afterload, with an ensuing increase in the cardiac index and in systemic perfusion [32-34]. The current models were not exclusively developed for TAVR. Thus, a score dedicated to these high-risk patients is welcome. Meanwhile, AKI preventive measures, such as low contrast volume, should be recommended. Prehydration should be performed with caution due to the risk of worsening heart failure, and acetylcysteine showed no benefit for the prevention of AKI [35].

\section{Limitations}

This is a multicentric observational study reported by the individual centers and has the limitations associated with retrospective analysis. So, a considerable number of 
patients were excluded due to lack of data, and it can represent a selection bias. As other national registries, the data collection shares the weaknesses of the study design. Thus, potentially informative data including acetylcysteine administration, hydration, rapid pacing frequency, duration, and the pacing rate might not have been included, despite the possible impact of these measures [36]. However, self-expandable prostheses were implanted in $70.5 \%$ of patients, and it may have reduced the impact of rapid pacing on outcomes. Information on the amount of contrast used in computed tomography scan is also not included in the registry, but patients are usually submitted to computed tomography scan prior to hospitalizations. Nevertheless, this is a large study with real-world data. Also, our population was predominantly of high surgical risk, and our findings cannot be extrapolated to other surgical risk status.

\section{Conclusion}

None of the current models demonstrated validity in detecting AKI when its lower grades were evaluated. CR4EATME3AD3 was the best score in predicting moderate to severe AKI after TAVR. These findings suggest that contrast-induced AKI may not be the only factor related to kidney injury after TAVR.

\section{Statement of Ethics}

The study protocol was conducted in accordance with the Declaration of Helsinki and was approved by each institution's Ethics Committee under protocol number 05676012.4.1001.00701. All patients have given their written informed consent to participate in the study.

\section{Conflict of Interest Statement}

José A. Mangione: proctor for Edwards Lifesciences and Medtronic. Fabio S. Brito Jr: proctor for Edwards Lifesciences and Medtronic. Alexandre A.C. Abizaid: proctor for Edwards Lifesciences and Boston Scientific. Paulo Caramori: proctor for Medtronic.

\section{Funding Sources}

The study was sponsored by Sociedade Brasileira de Hemodinâmica e Cardiologia Intervencionista, São Paulo, SP, Brazil.

\section{Author Contributions}

Vitor E.E. Rosa: design of the work; acquisition, analysis, interpretation of data, and drafting and revising the work. Carlos M. Campos: design of the work; acquisition, analysis, interpretation of data, and revising the work. Antonio Bacelar, José A. Mangione, Vinicius Esteves, and Paulo Caramori: acquisition of data and revising the work. Alexandre A.C. Abizaid and Pedro A. Lemos: interpretation of data and revising the work. Roney O. Sampaio, Flávio Tarasoutchi, and Roxana Mehran: revising the work. Fabio S. Brito Jr: design of the work, analysis and interpretation of data, and revising the work.

\section{References}

1 Baumgartner H, Falk V, Bax JJ, De Bonis M, Hamm C, Holm PJ, et al. 2017 ESC/EACTS guidelines for the management of valvular heart disease. Eur Heart J. 2017;38(36):2739-91.

2 Nishimura RA, Otto CM, Bonow RO, Carabello BA, Erwin JP 3rd, Fleisher LA, et al. 2017 AHA/ACC focused update of the 2014 AHA/ ACC guideline for the management of patients with valvular heart disease: a report of the American College of Cardiology/American Heart Association task force on clinical practice guidelines. J Am Coll Cardiol. 2017 Jun 20;70(25):252-89.

3 Serruys PW, Modolo R, Reardon M, Miyazaki Y, Windecker S, Popma J, et al. One-year outcomes of patients with severe aortic stenosis and an STS PROM of less than three percent in the SURTAVI trial. EuroIntervention. 2018;14(8):877-83.

4 Kolte D, Vlahakes GJ, Palacios IF, Sakhuja R, Passeri JJ, Inglessis I, et al. Transcatheter versus surgical aortic valve replacement in low- risk patients. J Am Coll Cardiol. 2019;74(12): 1532-40.

5 Mack MJ, Leon MB, Thourani VH, Makkar R, Kodali SK, Russo M, et al. Transcatheter aortic-valve replacement with a balloon-expandable valve in low-risk patients. N Engl J Med. 2019;380(18):1695-705.

6 Popma JJ, Deeb GM, Yakubov SJ, Mumtaz M, Gada H, O’Hair D, et al. Transcatheter aorticvalve replacement with a self-expanding valve in low-risk patients. N Engl J Med. 2019; 380(18):1706-15.

7 Thyregod HGH, Ihlemann N, Jørgensen TH, Nissen H, Kjeldsen BJ, Petursson P, et al. Fiveyear clinical and echocardiographic outcomes from the nordic aortic valve intervention (NOTION) randomized clinical trial in lower surgical risk patients. Circulation. 2019.

8 Gargiulo G, Capodanno D, Sannino A, Perrino C, Capranzano P, Stabile E, et al. Moderate and severe preoperative chronic kidney disease worsen clinical outcomes after trans- catheter aortic valve implantation: meta-analysis of 4,992 patients. Circ Cardiovasc Interv. 2015 Feb;8(2):e002220.

9 Gargiulo G, Sannino A, Capodanno D, Perrino C, Capranzano P, Barbanti M, et al. Impact of postoperative acute kidney injury on clinical outcomes after transcatheter aortic valve implantation: a meta-analysis of 5,971 patients. Catheter Cardiovasc Interv. 2015 Sep;86(3):518-27.

10 Kappetein AP, Head SJ, Genereux P, Piazza $\mathrm{N}$, van Mieghem NM, Blackstone EH, et al. Updated standardized endpoint definitions for transcatheter aortic valve implantation: the valve academic research consortium-2 consensus document. EuroIntervention. 2012 Nov 22;8(7):782-95.

11 Nunes Filho ACB, Katz M, Campos CM, Carvalho LA, Siqueira DA, Tumelero RT, et al. Impact of acute kidney injury on short- and longterm outcomes after transcatheter aortic valve implantation. Rev Esp Cardiol. 2019;72(1):21-9. 
12 de Brito FS Jr, Carvalho LA, Sarmento-Leite R, Mangione JA, Lemos P, Siciliano A, et al. Outcomes and predictors of mortality after transcatheter aortic valve implantation: results of the Brazilian registry. Catheter Cardiovasc Interv. 2015 Apr;85(5):E153-62.

13 Levey A, Greene T, Kusek J, Beck G; Group MS. A simplified equation to predict glomerular filtration rate from serum creatinine. J Am Soc Nephrol. 2000;11(Suppl 2):155.

14 Azarbal A, Leadholm KL, Ashikaga T, Solomon RJ, Dauerman HL. Frequency and prognostic significance of acute kidney recovery in patients who underwent transcatheter aortic valve implantation. Am J Cardiol. 2018; 121(5):634-41.

15 Cigarroa RG, Lange RA, Williams RH, Hillis LD. Dosing of contrast material to prevent contrast nephropathy in patients with renal disease. Am J Med. 1989 Jun;86(6 Pt 1):64952.

16 Laskey WK, Jenkins C, Selzer F, Marroquin OC, Wilensky RL, Glaser R, et al. Volume-tocreatinine clearance ratio: a pharmacokinetically based risk factor for prediction of early creatinine increase after percutaneous coronary intervention. J Am Coll Cardiol. 2007 Aug 14;50(7):584-90.

17 Capodanno D, Ministeri M, Dipasqua F, Dalessandro V, Cumbo S, Gargiulo G, et al. Risk prediction of contrast-induced nephropathy by ACEF score in patients undergoing coronary catheterization. J Cardiovasc Med. 2016 Jul;17(7):524-9.

18 Fu N, Li X, Yang S, Chen Y, Li Q, Jin D, et al. Risk score for the prediction of contrast-induced nephropathy in elderly patients undergoing percutaneous coronary intervention. Angiology. 2013 Apr;64(3):188-94.

19 Mehran R, Aymong ED, Nikolsky E, Lasic Z, Iakovou I, Fahy M, et al. A simple risk score for prediction of contrast-induced nephropathy after percutaneous coronary intervention: development and initial validation. J Am Coll Cardiol. 2004 Oct 6;44(7):1393-9.

20 Genereux P, Kodali SK, Green P, Paradis JM, Daneault B, Rene G, et al. Incidence and effect of acute kidney injury after transcatheter aortic valve replacement using the new valve academic research consortium criteria. Am J Cardiol. 2013 Jan 1;111(1):100-5.
21 Ferro CJ, Law JP, Doshi SN, de Belder M, Moat N, Mamas M, et al. Dialysis following transcatheter aortic valve replacement: risk factors and outcomes: an analysis from the UK TAVI (transcatheter aortic valve implantation) registry. JACC Cardiovasc Interv. 2017;10(20):2040-7.

22 Ma M, Gao WD, Gu YF, Wang YS, Zhu Y, He Y. Clinical effects of acute kidney injury after transcatheter aortic valve implantation: a systematic review and meta-analysis. Intern Emerg Med. 2019;14(1):161-75.

23 Attard S, Buttigieg J, Galea S, Mintoff M, Farrugia $\mathrm{E}$, Cassar $\mathrm{A}$. The incidence, predictors, and prognosis of acute kidney injury after transcatheter aortic valve implantation. Clin Nephrol. 2018;90(6):373

24 Adamo M, Provini M, Fiorina C, Giannini C, Angelillis M, Testa L, et al. Interaction between severe chronic kidney disease and acute kidney injury in predicting mortality after transcatheter aortic valve implantation: insights from the Italian clinical service project. Catheter Cardiovasc Interv. 2020;96(7): $1500-8$.

25 Janella BL, Campos CM, Caixeta A, Almeida BO, Brito FS Jr, Abizaid A, et al. Assessment of long-term mortality in patients with complex coronary artery disease undergoing percutaneous intervention: comparison of multiple anatomical and clinical prognostic risk scores. EuroIntervention. 2017;13(10):1177-84.

26 Hirsch R, Dent C, Pfriem H, Allen J, Beekman $\mathrm{RH}, \mathrm{Ma} \mathrm{Q}$, et al. NGAL is an early predictive biomarker of contrast-induced nephropathy in children. Pediatr Nephrol. 2007;22(12): 2089-95.

27 Ling W, Zhaohui N, Ben H, Leyi G, Jianping L, Huili D, et al. Urinary IL-18 and NGAL as early predictive biomarkers in contrast-induced nephropathy after coronary angiography. Nephron Clin Pract. 2008;108(3):c17681.

28 Ren L, Ji J, Fang Y, Jiang SH, Lin YM, Bo J, et al. Assessment of urinary $\mathrm{N}$-acetyl- $\beta$ glucosaminidase as an early marker of contrast-induced nephropathy. J Int Med Res. 2011;39(2):647-53.
29 Vijayasimha M, Padma V, Mujumdar SK, Satyanarayana PVV, Yadav A. Kidney injury molecule-1: a urinary biomarker for contrastinduced acute kidney injury. Med J DY Patil Univ. 2014;7(3):321.

30 Dusse F, Edayadiyil-Dudásova M, Thielmann M, Wendt D, Kahlert P, Demircioglu E, et al. Erratum to: "early prediction of acute kidney injury after transapical and transaortic aortic valve implantation with urinary G1 cell cycle arrest biomarkers". BMC Anesthesiol. 2015; 16(1):82-12.

31 Zaouter C, Priem F, Leroux L, Bonnet G, Bats ML, Beauvieux MC, et al. New markers for early detection of acute kidney injury after transcatheter aortic valve implantation. Anaesth Crit Care Pain Med. 2018;37(4):31926.

32 Hahn RT, Pibarot P, Stewart WJ, Weissman NJ, Gopalakrishnan D, Keane MG, et al. Comparison of transcatheter and surgical aortic valve replacement in severe aortic stenosis: a longitudinal study of echocardiography parameters in cohort A of the PARTNER trial (placement of aortic transcatheter valves). J Am Coll Cardiol. 2013 Jun 25; 61(25):2514-21.

33 Keles T, Ayhan H, Durmaz T, Sari C, Aslan AN, Erdogan KE, et al. Improvement in renal functions with transcatheter aortic valve implantation. J Geriatr Cardiol. 2013 Dec;10(4): $317-22$.

34 Faillace BLR, Ribeiro HB, Campos CM, Truffa AAM, Bernardi FL, Oliveira MDP, et al. Potential of transcatheter aortic valve replacement to improve post-procedure renal function. Cardiovasc Revasc Med. 2017 Oct-Nov; 18(7):507-11.

35 Weisbord SD, Gallagher M, Jneid H, Garcia S, Cass A, Thwin S-S, et al. Outcomes after angiography with sodium bicarbonate and acetylcysteine. N Engl J Med. 2018;378(7):60314.

36 Fefer P, Bogdan A, Grossman Y, Berkovitch A, Brodov Y, Kuperstein R, et al. Impact of rapid ventricular pacing on outcome after transcatheter aortic valve replacement. J Am Heart Assoc. 2018;7(14):e009038. 